\title{
New quinoxaline derivative as a green corrosion inhibitor for mild steel in mild acidic medium: Electrochemical and theoretical studies
}

\author{
T. Laabaissi, ${ }^{1}$ F. Benhiba, ${ }^{1}$ Z. Rouifi, ${ }^{1}$ M. Missioui, ${ }^{2}$ K. Ourrak, ${ }^{3}$ \\ H. Oudda, ${ }^{1}$ Y. Ramli, ${ }^{2}$ I. Warad, ${ }^{4}$ M. Allali ${ }^{5}$ and A. Zarrouk ${ }^{6 *}$
}

${ }^{1}$ Laboratory of Separation Procedures, Faculty of Sciences, Ibn Tofail University, Kenitra, Box 133, Kenitra, Morocco

${ }^{2}$ Laboratory of Medicinal Chemistry, Faculty of Medicine and Pharmacy, Mohammed V University, Rabat, 10170 Rabat, Morocco

${ }^{3}$ Laboratory of Physical Chemistry, Faculty of Sciences, Moulay Ismail University, Meknès, Morocco

${ }^{4}$ Department of Chemistry, AN-Najah National University P.O. Box 7, Nablus, Palestine

${ }_{5}^{5}$ Institut Supérieur des Professions Infirmières et Techniques de Santé, ISPITS-Fès,

Hôpital Elghassani, Fes, Morocco

${ }^{6}$ Laboratory of Materials, Nanotechnology and Environment, Faculty of Sciences, Mohammed V University, Av. Ibn Battouta, Box 1014 Agdal-Rabat, Morocco

*E-mail: azarrouk@gmail.com

\begin{abstract}
The influence of new quinoxaline derivative namely $(E)$-3-(4-methylstyryl)quinoxalin-2(1H)one (QNMS) on the corrosion of mild steel in $1 \mathrm{M} \mathrm{HCl}$ was studied using using Tafel polarization and electrochemical impedance spectroscopy. Quantum chemical calculations were performed using methods based on density functional theory (DFT / B3LYP) and Monte Carlo simulations (MCs). The inhibitor studied [(E)-3-(4-methylstyryl)quinoxalin-2(1H)-one (QNMS)] showed a maximum inhibition efficiency of $91 \%$ at $10^{-3} \mathrm{M}$. Adsorption of QNMS on mild steel surface follows the Langmuir adsorption isotherm in order to discover the mode of adsorption process, various thermodynamic and activation parameters were evaluated. Potentiodynamic polarization studies show that QNMS compound acts as a mixed inhibitor. Data obtained from EIS measurements were analyzed to model the corrosion inhibition process through the appropriate equivalent circuit model. The EIS data bring that, the development of a protective layer of QNMS increases the charge transfer resistance and decreases the double layer capacitance of mild steel in acid medium. Quantum chemical calculations were employed to study the electronic properties of QNMS to ascertain the correlation between the inhibitory effect and the molecular structure. Both the experimental and theoretical ( $E_{\mathrm{Homo}}, E_{\mathrm{LUMO}}, \Delta E, \mu, \Delta N, \ldots$ and Monte Carlo simulation) results are in good agreement with each other in this regard and confirm that QNMS is an effective inhibitor.
\end{abstract}


Key words: mild steel, $\mathrm{HCl}$, corrosion inhibition, quinoxaline, DFT, Monte Carlo simulations.

Received: November 27, 2018. Published: March 27, 2019

doi: $\underline{10.17675 / 2305-6894-2019-8-2-6}$

\section{Introduction}

The corrosion of mild steel, in acidic medium and in particular in hydrochloric acid, is often a very serious problem in many industrial installations; it is imperative to moderate this harmful phenomenon by using organic products as corrosion inhibitors. Several researchers have worked together to develop effective inhibitors to secure metallic materials against corrosion $[1,2]$. The choice of suitable inhibitors depends mainly on the formulation as a reasonable use in various environments. Organic compounds characterized by distinct functional groups and heteroatoms such as nitrogen, oxygen, sulfur and aromatic rings are considered as effective organic inhibitors to protect the metal against corrosion $[3,4]$.

The orientation and the shape of the molecule are decisive parameters in the inhibition of corrosion. The mode of action of these inhibitors generally results from their adsorption (chemical and/or physical) on the surface of the metal. The adsorption depends essentially on steric factors, the aromaticity and the structural properties of the organic compounds studied, such as the presence of $\pi$-electrons and heteroatoms, which favor the adsorption of inhibitory molecules on the surface of the steel [5]. For this reason, research on the adsorption mode and the corrosion inhibition properties of promising novel organic compounds as corrosion inhibitors appear as a continuous and dynamic domain of research [6-9]. Many drugs and biologically important compounds contain quinoxalines [12] as essential units or fragments. These compounds have been reported to have a broad spectrum of biological activities, including antitumor, antiepileptic, antibiotic and anticancer activities [13]. The inhibitory effects of quinoxaline on metal corrosion have also been established $[14,15]$.

That's why we chose this family of quinoxaline. This article contributes to the study of corrosion inhibition of mild steel by a of quinoxaline compound in hydrochloric acid medium (1 M). The molecular structure of this inhibitor is shown in Figure 1. To carry out this study, we used stationary and transient electrochemical methods. Then, quantum chemistry calculations by the functional theory of density and Monte Carlo simulation were performed to explain why small modifications of the QNMS structure has a significant effect on their inhibition efficiency. These two techniques have been established as being very effective and the module adapted to acquire new physical knowledge in their real inhibition mechanism [16]. 


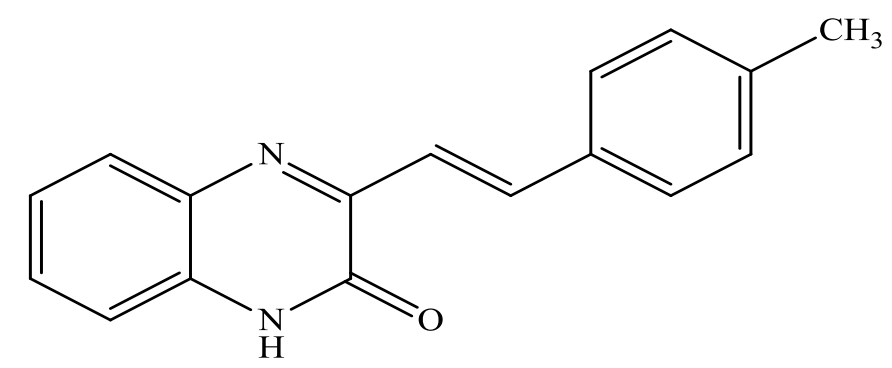

Figure 1. Chemical structure of $(E)$-3-(4-methylstyryl)quinoxalin-2(1H)-one (QNMS).

\section{Experiential}

\subsection{Materials}

Mild steel (MS) specimen of chemical composition 0.0760 wt.\% C, 0.1920 wt.\% Mn, 0.0120 wt.\% P, 0.0260 wt.\% Si, 0.0500 wt.\% Cr, 0.0230 wt.\% Al, and balance with Fe was in use in the present application to bear out all electrochemical and surface measurements. The exposed areas were $1 \mathrm{~cm}^{2}$ for electrochemical experiment, respectively. The test solution of $1 \mathrm{M} \mathrm{HCl}$ was processed by dilution of analytical grade $\mathrm{HCl}$ (37\%, MERCK) with elaborated water.

\subsection{Synthesis}

The bibliography, reports various methods to prepare styrylquinoxalines $[17,18]$. For our part, we tried a different synthetic ways which consists on reacting 3-methylquinoxaline-2one with the aromatic aldehyde. This method was carried out in the absence of solvent, for that we had the possibility to isolate the expected compound with excellent yield, ranging between $76 \%$ and $93 \%$. Indeed, $12.5 \mathrm{mmol}$ of 3-methylquinoxaline-2-one is used with to $50 \mathrm{mmol}$ of benzaldehyde for 2 hours at the boiling temperature of the latter. At the end of the reaction, the solid compound is allowed to cool and then heated at $100^{\circ} \mathrm{C}$ for 10 minutes in $80 \mathrm{~mL}$ of ethanol. The product is precipitated in powder form and then filtered.

The principal NMR spectral data and melting point of $(E)$-3-(4-methylstyryl)quinoxalin-2(1H)-one is: Yield $=90 \%, \mathrm{mp}=255^{\circ} \mathrm{C} .{ }^{1} \mathrm{H}$ NMR $\left(300 \mathrm{MHz}, \mathrm{DMSO} \mathrm{d}_{6}\right): \delta$ $7.63(\mathrm{~d}, 1 \mathrm{H}, \mathrm{CH}$ ethylenically, $3 J=16.2 \mathrm{~Hz}) 8.05(\mathrm{~d}, 1 \mathrm{H}, \mathrm{CH}$ ethylenically, $3 J=16.2 \mathrm{~Hz})$ respectively.

\subsection{Electrochemical measurements}

A three-electrode glass cell assembled with a platinum counter-electrode, a saturated calomel reference, and mild steel with a $1 \mathrm{~cm}^{2}$ display area as the working electrode, respectively, was used to realize all electrochemical measurements. Electrochemical measurements were performed using a Gamry galvanostat (G-300) potentiometer with EIS software (Gamry Instruments Inc., USA). The Echem Analyst package, N 5.0 was used to adjust and analyze the data. Before, each measurement allowed the specimens to corrode 
freely and their OCPs were measured over time ( $200 \mathrm{~s})$ to obtain stable potential (OCP). A scan rate of potential was $0.5 \mathrm{mV} \cdot \mathrm{s}^{-1}$ and potential was scanned in the range of -800 to $-200 \mathrm{mV} / \mathrm{SCE}$ relative to the corrosion potential. From the Echem Analyst 5.0 software package installed in the instrument, polarization parameters such as corrosion potential $\left(E_{\text {corr }}\right)$, corrosion current $\left(i_{\text {corr }}\right)$, anodic $\left(\beta_{\mathrm{a}}\right)$ and cathodic Tafel slopes $\left(\beta_{\mathrm{c}}\right)$ were obtained by extrapolation. Inhibition efficiency $(I E \%)$ was calculated using $i_{\text {corr }}$ calculated using the following relationship:

$$
I E_{\text {Tafel }}(\%)=\frac{i_{\text {corr }}^{0}-i_{\text {corr }}^{\mathrm{i}}}{i_{\text {corr }}^{0}} \times 100
$$

where $i_{\text {corr }}^{0}$ and $i_{\text {corr }}^{\mathrm{i}}$ are the corrosion current densities in the absence and presence of QNMS, respectively [19].

Spectroscopic electrochemical impedance (EIS) measurements were performed using an $\mathrm{AC}$ voltage of amplitude $10 \mathrm{mV}$ at its open circuit potential (OCP) in the frequency range $100 \mathrm{kHz}$ to $0.01 \mathrm{~Hz}$. The inhibition efficiency of QNMS was calculated from the charge transfer resistance values using the following formula:

$$
I E_{\mathrm{EIS}}(\%)=\frac{R_{\mathrm{ct}}^{\mathrm{i}}-R_{\mathrm{ct}}^{0}}{R_{\mathrm{ct}}^{i}} \times 100
$$

where $R_{\mathrm{ct}}^{0}$ and $R_{\mathrm{ct}}^{\mathrm{i}}$ are the charge transfer resistance in the absence and in the presence of inhibitor, respectively.

\section{Results and discussion}

\subsection{Tafel polarization study}

DC methods are appropriate for monitoring the advancement and mechanisms of the anodic and cathodic partial reactions as well as identifying the effect of an additive on either partial reaction. DC experiments were make to establish the effect of the anodic $\left(\mathrm{Fe} \rightarrow \mathrm{Fe}^{2+}+2 \mathrm{e}^{-}\right)$and cathodic $\left(2 \mathrm{H}^{+}+2 \mathrm{e}^{-} \rightarrow \mathrm{H}_{2}\right)$ partial reactions of the corrosion process. Typical anodic and cathodic polarization curves obtained for the corrosion of MS in $1 \mathrm{M} \mathrm{HCl}$ solution with and without of various concentrations of QNMS are presented in Figure 2. The curves showed that the introduction of QNMS to $1 \mathrm{M} \mathrm{HCl}$ solution has a modest influence on both anodic and cathodic half reactions, although cathodic influence appeared much pronounced. Corrosion current densities $\left(i_{\text {corr }}\right)$, corrosion potential $\left(E_{\text {corr }}\right)$, anodic $\left(\beta_{\mathrm{a}}\right)$ and the cathodic Tafel slope $\left(\beta_{\mathrm{c}}\right)$ derived from the polarization curves are given in Table 1. 


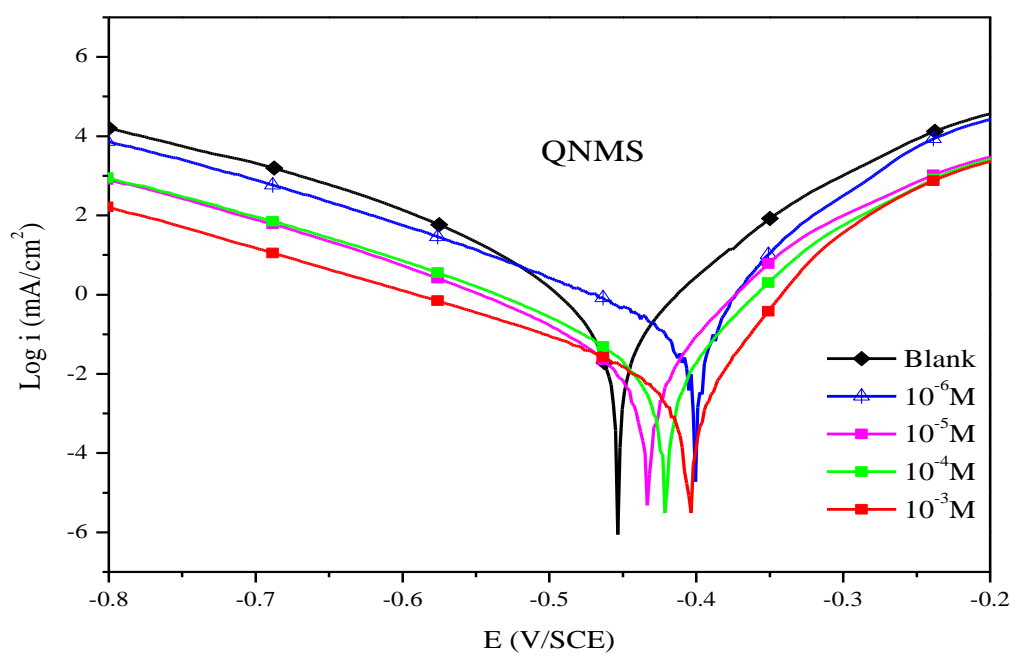

Figure 2. Polarization curves of mild steel in $1 \mathrm{M} \mathrm{HCl}$ with and with presence of inhibitor at $303 \mathrm{~K}$.

Table 1. Electrochemical parameters and inhibitory corrosion efficacy of mild steel in $1 \mathrm{M} \mathrm{HCl}$ with and without addition of different concentrations of QNMS at $303 \mathrm{~K}$.

\begin{tabular}{|c|c|c|c|c|c|c|}
\hline Medium & $\begin{array}{l}\text { Conc. } \\
\text { (M) }\end{array}$ & $\begin{array}{c}-E_{\text {corr }} \\
(\mathrm{mV} / \mathrm{SCE})\end{array}$ & $\begin{array}{c}-\boldsymbol{\beta}_{\mathrm{c}} \\
\left(\mathbf{m V} \operatorname{dec}^{-1}\right)\end{array}$ & $\begin{array}{c}\boldsymbol{\beta}_{\mathbf{a}} \\
\left(\mathbf{m V} \mathbf{d e c}^{-1}\right)\end{array}$ & $\begin{array}{c}i_{\mathrm{corr}} \\
\left(\mu \mathrm{A} \mathrm{cm}^{-2}\right)\end{array}$ & $\begin{array}{c}I E_{\text {Tafel }} \\
(\%)\end{array}$ \\
\hline $\mathrm{HCl}$ & 1 & 471 & 170 & 123 & 564.0 & - \\
\hline \multirow{4}{*}{ QNMS } & $10^{-3}$ & 406 & 103 & 47 & 47.0 & 91.6 \\
\hline & $10^{-4}$ & 425 & 91 & 56 & 80.0 & 85.8 \\
\hline & $10^{-5}$ & 438 & 92 & 55 & 112.8 & 80.0 \\
\hline & $10^{-6}$ & 405 & 122 & 53 & 163.5 & 71.0 \\
\hline
\end{tabular}

It was illustrated from the data that the addition of QNMS decreased the corrosion current density $\left(i_{\text {corr }}\right)$. The decrease may be due to the adsorption of the inhibitor on metal/acid interface. The maximum inhibition was obtained at the concentration of $10^{-3} \mathrm{M}$ $(91.6 \%)$. From Figure 2, it is also cleared that both cathodic reduction and anodic metal dissolution reactions were inhibited when the QNMS compound were added to the acid solution. This effect is more pronounced when the added compound concentration increases. These results suggest that quinoxaline reduce both anodic dissolution and retard $\mathrm{H}^{+}$proton reduction. An inhibitor can be classified as a cathodic or anodic type if the corrosion potential displacement is greater than $85 \mathrm{mV}_{\mathrm{SCE}}$ with respect to the corrosion potential of the control solution [20-22]. In the presence of the compound tested, the corrosion potential of the mild steel was reduced to the negative side only of $66 \mathrm{mV}_{\mathrm{SCE}}$ for QNMS. This indicates that the organic compound act as a mixed type inhibitor. The 
cathodic Tafel slope $\left(\beta_{c}\right)$ show slight changes with the addition of QNMS, which suggests that the inhibiting action occurred by simple blocking of the available cathodic sites on the metal surface, which lead to a decrease in the exposed area necessary for hydrogen evolution.

\subsection{Impedance study}

AC technique provides a new and performing method to characterize the film coverage on the electrode, which is related to charge transfer resistance $\left(R_{\mathrm{ct}}\right)$. The interface capacitance can also be used to establish the film quality [23-27]. It is known that the coverage of an organic substance on the metal surface not only depends on the structure of the inhbitor organic and the nature of the metal, but likewise on the experimental conditions such as immersion time and concentration of adsorbent [26, 27].

Figures 3 and 4 represented as Nyquist, Bode plots and phase angle, respectively, show the impedance spectra for MS corrosion in $\mathrm{HCl}$ solution with and without various concentrations of QNMS. In all the studied frequency range, the Nyquist plots (Figure 3 \& Figure 4) show single semicircles which correspond to one time constant in Bode plots. Inspection of Figure 3 revealed that increasing concentration of the QNMS results in an increase in the size of the semicircles. This increase is indicative of the MS surface protection in $\mathrm{HCl}$ solution afforded by the adsorbed QNMS. This implies that the higher concentration inhibits $\mathrm{MS}$ corrosion in $\mathrm{HCl}$ solution while the lower concentration accelerates the dissolution of MS in the studied medium.

All the impedance spectra exhibit one single depressed semicircle, and the diameter of semicircle increases with the increase in QNMS concentration. The semi-circular appearance shows that the corrosion of steel is controlled by the charge transfer and the presence of QNMS does not change the mechanism of steel dissolution [28, 29]. The semicircles are not perfect, but depressed with centers under the real axis. The observed depression with and without QNMS for the Nyquist semicircle with center under the real axis is typical for solid metal electrodes that show frequency dispersion of the impedance data. Such behavior characteristic for solid electrodes and often referred to frequency dispersion could be attributed to different physical phenomena such as roughness and inhomogeneities of the solid surfaces, impurities, grain boundaries and distribution of the surface active sites [30]. Therefore, a constant phase element (CPE) instead of a capacitive element is used to get a more accurate fit of the experimental data set. The impedance function of a CPE is defined by the mathematical expression given below [31]:

$$
Z_{\mathrm{CPE}}=Q^{-1}(i \omega)^{-n}
$$

where $Q\left(\Omega^{-1} \cdot \mathrm{s}^{n} \cdot \mathrm{cm}^{-2}\right)$ is the magnitude of the CPE, $\omega\left(\mathrm{rad} \cdot \mathrm{s}^{-1}\right)$ is the sine wave modulation angular frequency, $i^{2}=-1$ is the imaginary number and $n$ is an empirical exponent which measures the deviation from the ideal capacitive behaviour $[32,33]$. 
Depending on the values of $n$, CPE can represent resistance $(n=0)$, capacitance $(n=1)$, inductance $(n=-1)$ and Warburg impedance $(n=0.5)$ [34-38].

The transfer function is thus represented by an equivalent circuit, having only one time constant (Figure 5). Parallel to the double layer capacitance (simulated by a CPE) is the charge transfer resistance symbolized by $R_{\mathrm{ct}}$, and $R_{\mathrm{s}}$ is the electrolyte resistance. Excellent fit with this model was obtained for all experimental data. It is clear that the measured impedance plot is in accordance with that calculated by the used equivalent circuit model. It means that the equivalent circuit model proposed in Figure 5 could reasonably represent the charge transfer and metal/solution interface features related to the corrosion process of iron in acidic solution containing QNMS.

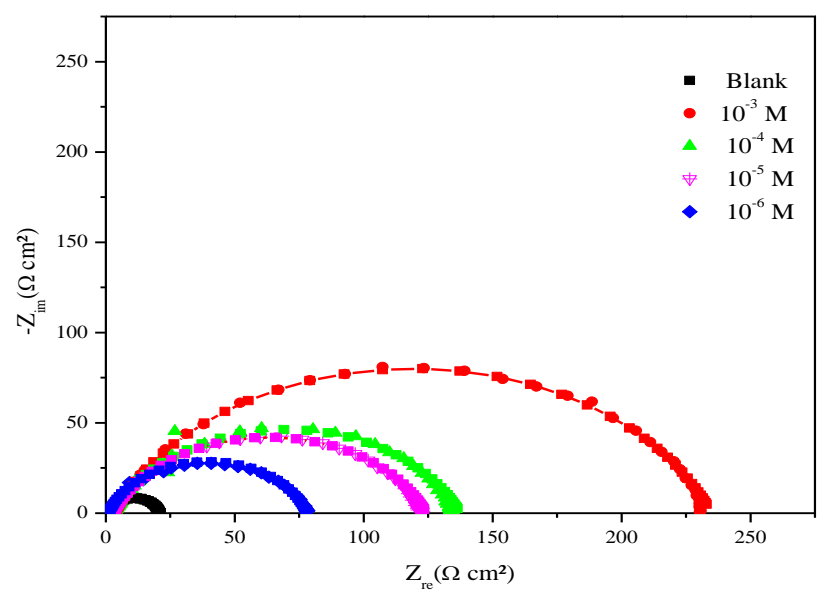

Figure 3. Impedance diagrams of mild steel in $1 \mathrm{M} \mathrm{HCl}$ without and with addition of different concentrations of QNMS at $303 \mathrm{~K}$.

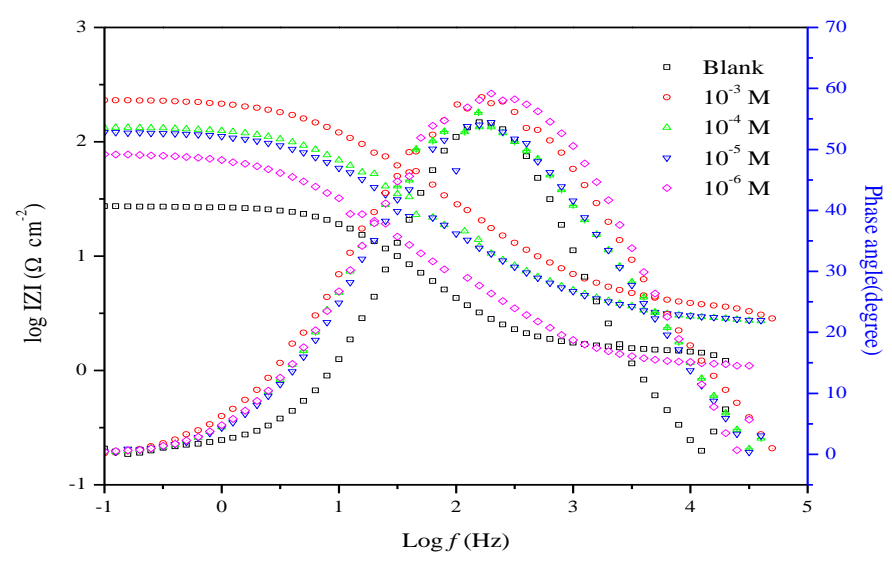

Figure 4. Bode and phase angle curves at the steel/quinoxaline/ $\mathrm{HCl}$ interface at $303 \mathrm{~K}$. 


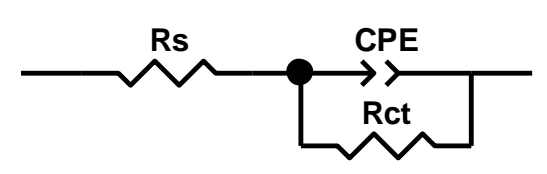

Figure 5. Equivalent electrical circuit of the mild steel/solution interface.

Table 2 contains all the impedance parameters obtained from the simulation of experimental impedance data, including $R_{\mathrm{s}}, R_{\mathrm{ct}}, Q, n$ and $I E_{\mathrm{EIS}}(\%)$. In the table are shown also the calculated double layer capacitance values, $C_{\mathrm{dl}}$, derived from the CPE parameters according to substitute [39]:

$$
C_{\mathrm{dl}}=\left(Q\left(R_{\mathrm{ct}}\right)^{1-n}\right)^{1 / n}
$$

Inspection of the results in Table 2 indicates that the $R_{\mathrm{ct}}$ value increased with the concentration of QNMS, reaching a maximum value of $231 \Omega \cdot \mathrm{cm}^{2}$ at $10^{-3} \mathrm{M}$. Also, the value of the proportional factor $Q$ of CPE varies in a regular manner with inhibitor concentration. The change of $R_{\mathrm{ct}}$ and $Q$ values can be related to the gradual replacement of water molecule ions by QNMS molecules on the surface and consequently to a decrease in the number of active sites necessary for the corrosion reaction [40]. Also, the addition of QNMS to the corrosive solution decreases the double layer capacitance $\left(C_{\mathrm{dl}}\right)$ (Table 2$)$. The double layer between the charged metal surface and the solution is considered as an electrical capacitor. The adsorption of QNMS on the MS surface decreases its electrical capacity because they displace the water molecules and other ions originally adsorbed on the surface. The decrease in this capacity with increase in QNMS concentrations may be attributed to the formation of a protective layer on the electrode surface [41]. The thickness of this protective layer increases with increase in QNMS concentration, since more QNMS will electrostatically adsorb on the electrode surface, resulting in a noticeable decrease in $C_{\mathrm{dl}}$. This trend is in accordance with Helmholtz model, given by the following equation [42]:

$$
C_{\mathrm{dl}}=\frac{\varepsilon_{0} \varepsilon}{d} S
$$

where $d$ is the thickness of the protective layer, $\varepsilon$ is the dielectric constant of the protective layer and $\varepsilon_{0}$ is the permittivity of free space $\left(8.854 \times 10^{-14} \mathrm{~F} \cdot \mathrm{cm}^{-1}\right)$. 
Table 2. Electrochemical parameters of the impedance diagram of mild steel in $1 \mathrm{M} \mathrm{HCl}$ in the absence and in the presence of quinoxaline at different concentrations at $303 \mathrm{~K}$.

\begin{tabular}{ccccccc}
\hline Medium & $\begin{array}{c}\text { Conc. } \\
(\mathbf{M})\end{array}$ & $\begin{array}{c}\boldsymbol{R}_{\mathrm{ct}} \\
\left(\boldsymbol{\Omega} \cdot \mathbf{c m}^{\mathbf{2}}\right)\end{array}$ & $\boldsymbol{n}$ & $\begin{array}{c}\boldsymbol{Q} \times \mathbf{1 0}^{\mathbf{4}} \\
\left(\boldsymbol{\Omega}^{-\mathbf{1}} \mathbf{s}^{\boldsymbol{n}} \cdot \mathbf{c m}^{-\mathbf{2}}\right)\end{array}$ & $\begin{array}{c}\boldsymbol{C}_{\mathbf{d l}} \\
\left(\boldsymbol{\mu} \mathbf{F} \cdot \mathbf{c m}^{-\mathbf{2}}\right)\end{array}$ & $\begin{array}{c}\boldsymbol{I E} \text { EIS } \\
(\boldsymbol{\%})\end{array}$ \\
\hline Blank & 1 & 20.5 & 0.890 & 2.061 & 104.8 & - \\
\hline \multirow{2}{*}{ QNMS } & $10^{-3}$ & 231.0 & 0.781 & 0.721 & 22.86 & 91.1 \\
& $10^{-4}$ & 134.0 & 0.772 & 0.881 & 23.70 & 84.7 \\
& $10^{-5}$ & 121.0 & 0.740 & 1.11 & 24.10 & 83.1 \\
\hline
\end{tabular}

\subsection{Adsorption isotherm}

The corrosion inhibition mechanism of QNMS on the mild steel surface in $1 \mathrm{M} \mathrm{HCl}$ solution can be investigated by the evaluation of adsorption isotherm. The interaction of QNMS molecules on the metal surface can be studied by investigating the mode of adsorption and the adsorption isotherm. Among different adsorption isotherms, the Langmuir adsorption isotherm is the most fundamental so was tested at first. The correlation between $\theta$ and QNMS concentration can be studied by Eq. 5 .

$$
\frac{C}{\theta}=\frac{1}{K}+C
$$

where $K$ is the equilibrium constant of the adsorption process, $C$ is the QNMS concentration and $\theta\left(I E_{\mathrm{EIS}} / 100\right)$ is the fraction of metal surface covered by the QNMS. According to Figure 6 and Table 3, the plot of $C / \theta$ versus $C$ yielded straight lines with a correlation coefficient $\left(R^{2}>0.9999\right)$ close to 1 suggesting that the adsorption of QNMS on the mild steel surface obeyed a Langmuir adsorption isotherm [43-46]. The applicability of the Langmuir adsorption isotherm to the adsorption of the QNMS on mild steel in $1 \mathrm{M}$ $\mathrm{HCl}$ confirms the formation of a multi-molecular adsorption layer, which prevents interaction between the adsorbate and the adsorbent. So other isotherms were not considered for further investigations. The value of the equilibrium constant $(\mathrm{K})$ was calculated from the interception of the straight line in Figure 6. The equilibrium constant is related to the standard free energy of adsorption $\left(\Delta G_{\mathrm{ads}}^{0}\right)$ with the following equation (Eq. 6):

$$
\Delta G_{\text {ads }}^{0}=-R T \ln \left(C_{\mathrm{H}_{2} \mathrm{O}} K\right)
$$

where the $C_{\mathrm{H}_{2} \mathrm{O}}=55.5 \mathrm{~mol} / \mathrm{L}$ in the solution. 


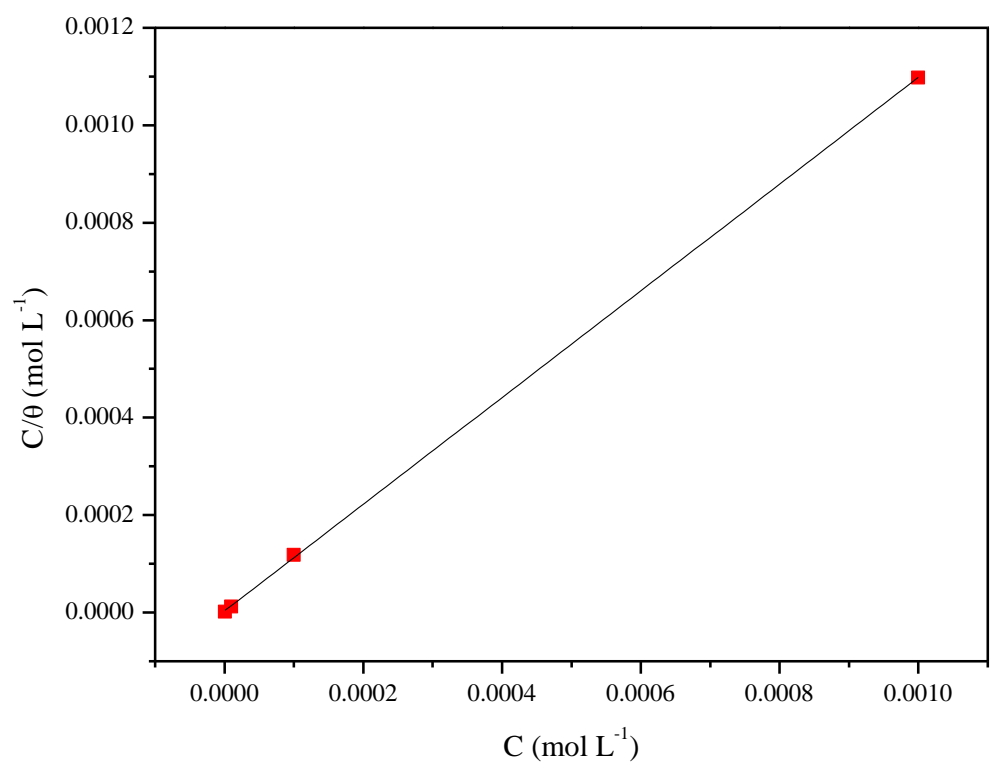

Figure 6. Langmuir adsorption isotherm for QNMS on mild steel in $1 \mathrm{M} \mathrm{HCl}$ at $303 \mathrm{~K}$.

Table 3. Langmuir adsorption parameters for QNMS at $303 \mathrm{~K}$.

\begin{tabular}{ccccc}
\hline Inhibitor & Slope & $\begin{array}{c}\boldsymbol{K} \\
(\mathbf{L} / \mathbf{m o l})\end{array}$ & $\boldsymbol{R}^{\mathbf{2}}$ & $\begin{array}{c}-\Delta \boldsymbol{G}_{\text {ads }}^{\mathbf{0}} \\
\left(\mathbf{k J} \cdot \mathbf{m o l}^{\mathbf{1}}\right)\end{array}$ \\
\hline QNMS & 1.09 & 319624.63 & 0.99992 & 42.05 \\
\hline
\end{tabular}

Generally, the energy values of $\Delta G_{\text {ads }}^{0}$ around $-20 \mathrm{~kJ} \cdot \mathrm{mol}^{-1}$ or less negative are associated with an electrostatic interaction between charged QNMS molecules and charged metal surface, i.e. physisorption; those of $-40 \mathrm{~kJ} \cdot \mathrm{mol}^{-1}$ or more negative involve charge sharing or transfer from the QNMS molecules to the metal surface to form a coordinate type bond, i.e. chemisorptions [22].

The negative estimations of $\Delta G_{\text {ads }}^{0}$ demonstrate that all the QNMS inhibitor is firmly adsorbed on the mild steel surface. The considered $\Delta G_{\text {ads }}^{0}$ value as delineated in Table 3 is lower than $-40 \mathrm{~kJ} \cdot \mathrm{mol}^{-1}$ which implies that the absorption process is of the chemisorption nature [47].

\subsection{Theoretical study of structure-activity relationship by DFT}

Quantum study is a method which helps to find the relationship between inhibition effect and molecular structure in the corrosion field [48]. In the context, DFT was employed to have an idea about the reaction mechanism (adsorption) which has a correlation with molecular structures. Therefore, gas phase optimized structures and distribution of electron 
density for frontier molecular orbital (FMO) namely highest occupied molecular orbital (HOMO) and lowest unoccupied molecular orbital (LUMO) of the neutral form of the investigated inhibitor molecule (QNMS) obtained using B3LYP functional with 6-311++G $(d, p)$ basis set [49] are shown in Figure 7. Quantum chemical calculations were performed using Gaussian 09 software [50]. It is evident from Figure 7 that the HOMO and LUMO electronic densities are distributed over the entire surface of the QNMS molecular structure. Indeed, which indicates that this molecule can to accept and give electrons at the same time.

Optimized molecular structure

HOMO

LUMO

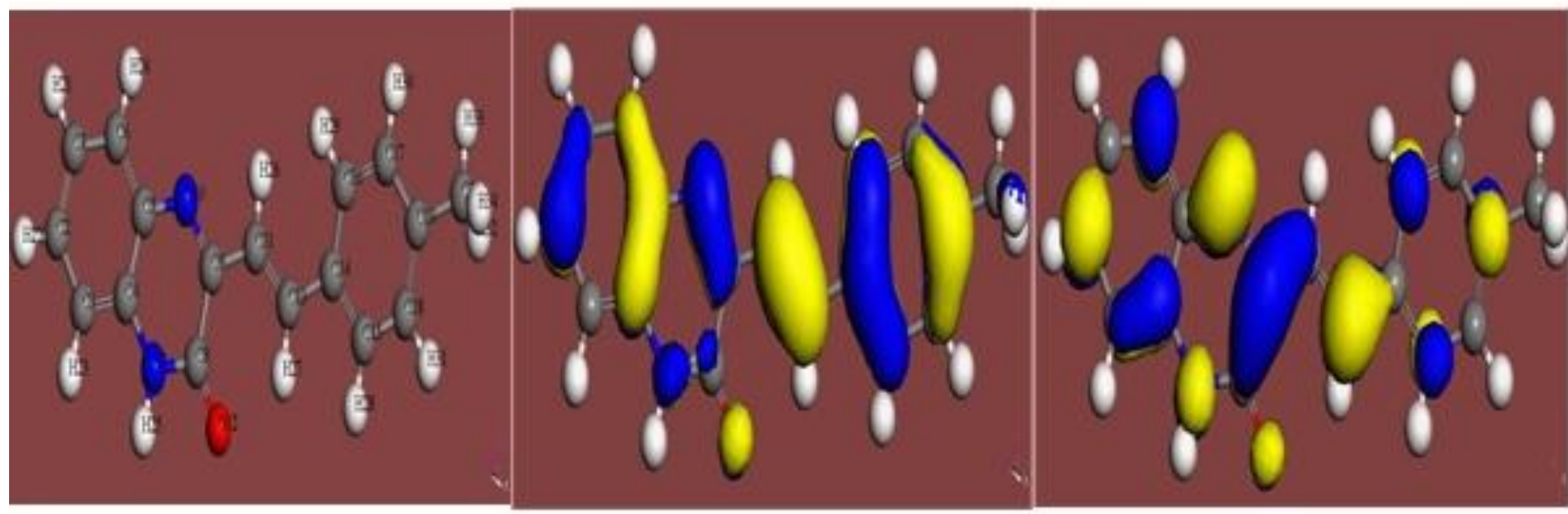

Figure 7. Optimized structure, HOMO and LUMO density distributions of QNMS.

The quantum chemical descriptors (QCD) containing the energy of $E_{\mathrm{LUMO}}$, the $E_{\mathrm{HOMO}}$, energy gap $\left(\Delta E_{\text {gap }}=E_{\text {LUMO }}-E_{\text {HOMO }}\right)$, the global hardness $(\eta)$, the dipole moment $(\mu)$ global electronegativity $(\chi)$, the electrophilicity index $(\omega)$ and the number of electrons transferred from the occupied orbitals of the inhibitor to no-occupied orbital's of the metal surface of the iron (110) ( $\triangle N 110$ with $Q$ ) were calculated and represented in Table 4. According to this table it is clear that the values of $E_{\mathrm{HOMO}}$ and $E_{\mathrm{LUMO}}$, which translates the chemical stability of the molecule. It is widely acknowledged that low $E_{\text {LUMO }}$ reveal the capacity of accepting electrons, while the power of donating electrons to electrons-acceptor can be shown by the high value of $E_{\mathrm{HOMO}}$ [51].

The value of $\Delta E_{\text {gap }}$ indicates the chemical reactivity of a molecule, and a lower value of energy gap reflects that studied molecule can be absorbed easily on metal surface.

From Table 6, the values of $E_{\text {Hомо }}(-5.542 \mathrm{eV}), E_{\mathrm{Lumo}}(-2.128 \mathrm{eV})$ and $\Delta E_{\mathrm{gap}}$ $(3.414 \mathrm{eV})$ have shown that the stability and overall reactivity of the inhibitor QNMS is to be taken in considerable. In addition, the dipole moment $(\mu)$ is another element reflecting the correlation between $\mu$ and inhibitory efficacy. According to the revision of the literature some authors [52], the low value of $\mu$ will enhance the accumulation of inhibitor on metal surface thus increase the inhibitory performance. The calculated minimum value of the dipole moment is equal 2.147 Debye for QNMS. There are other structural 
parameters, namely the global hardness $(\eta)$ and the global electronegativity $(\chi)$; their values are also listed in Table 6. So, the higher value of $\chi(3.835 \mathrm{eV})$ and the lower value of $\eta(1.707 \mathrm{eV})$ imply better inhibitive performance. On another side, the ability to donate and accept electrons is determined by $\Delta N_{110}$ and $W_{\text {inh }}$, respectively. From what we found in the literature if $\Delta N_{110}<3.6$, the inhibition efficiency increases with the increase in electrondonation ability to the metal surface. Indeed, the value of $\mathrm{w}$ is equal to $0.289 \mathrm{eV}$, which indicates that the compound QNMS is a corrective inhibitor against corrosion.

Table 4. QCD of QNMS inhibitor molecule calculated with the DFT/B3LYP/6-311++ G (d,p) method $[53,54]$.

\begin{tabular}{ccccc}
\hline Parameter & $\boldsymbol{E}_{\text {LUMO }}(\mathbf{e V})$ & $\boldsymbol{E}_{\text {HOMO }}(\mathbf{e V})$ & $\boldsymbol{\Delta} \boldsymbol{E}_{\text {gap }}(\mathbf{e V})$ & $\boldsymbol{\mu}(\mathbf{D})$ \\
\hline Value & -2.128 & -5.542 & 3.414 & 2.147 \\
\cline { 1 - 2 } & $\eta_{\text {inh }}=\frac{\Delta E_{\text {gap }}}{2}(\mathbf{e V})$ & $\chi_{\text {inh }}=-\frac{E_{\text {HOMO }}+E_{\text {LUMO }}}{2}$ & $\begin{array}{c}\omega_{\text {inh }}=\frac{\chi_{\text {inh }}^{2}}{2 \eta_{\text {inh }}} \\
(\mathbf{e V})\end{array}$ & $\Delta N_{110}=\frac{\phi-\chi_{\text {inh }}}{2 \eta_{\text {inh }}}$ \\
\hline Value & 1.707 & 3.835 & 4.308 & 0.289 \\
\hline
\end{tabular}

\subsection{Monte Carlo simulation}

Monte Carlo simulations were carried between the interactions the investigated F41 molecules on Fe (110) surface. Simulations of two molecules and systems using the COMPASS are made in an area of $(26.894 \times 26.894 \times 22.134 \AA)$ with periodic limit conditions, a super cell of $(13 \times 13)$, a slab thickness of $5 \AA$, a vacuum of $40 \AA$ forth the $C$ axis and we studied six layers of Fe to assure that the surface profundity was greater than the non-cut in use in the calculation [55].

To see how adsorbed the inhibitor QNMS on a metal surface of iron with the reticular plane (110) we realized the Monte Carlo simulation using the QNMS/500 $\mathrm{H}_{2} \mathrm{O} / 5 \mathrm{H}_{3} \mathrm{O}^{+}$/ $5 \mathrm{Cl}^{-} / \mathrm{Fe}(110)$ ) system. Figure 8 shows that the system is in chemical equilibrium with the most stable representation of the molecule studied. As shown in Figure 8, the inhibitor QNMS is adsorbed flat and parallel on the first layer of the iron metal. This indicates that the reactivity of this molecule is generalized over the entire molecular structure.

Adsorption energy $\left(E_{\text {ads }}\right)$ and the interaction energy of inhibitor-metal interactions, $E_{\text {int }}\left(E_{\text {int }}=-E_{\text {ads }}\right)$ [56] values for the studied system studied are combined in Table 5. From this table the negative value of the $E_{\text {ads }}$ and the large value of the $E_{\text {int }}$ of QNMS indicate that this inhibitor is well adsorbed on the metal surface of the iron (Fe (110)). The ratios of the adsorption energies $\mathrm{d} E_{\text {ads }} / \mathrm{d} N \mathrm{~N}$ of each element or molecule of the studied system are also listed in the table of Table 5. 


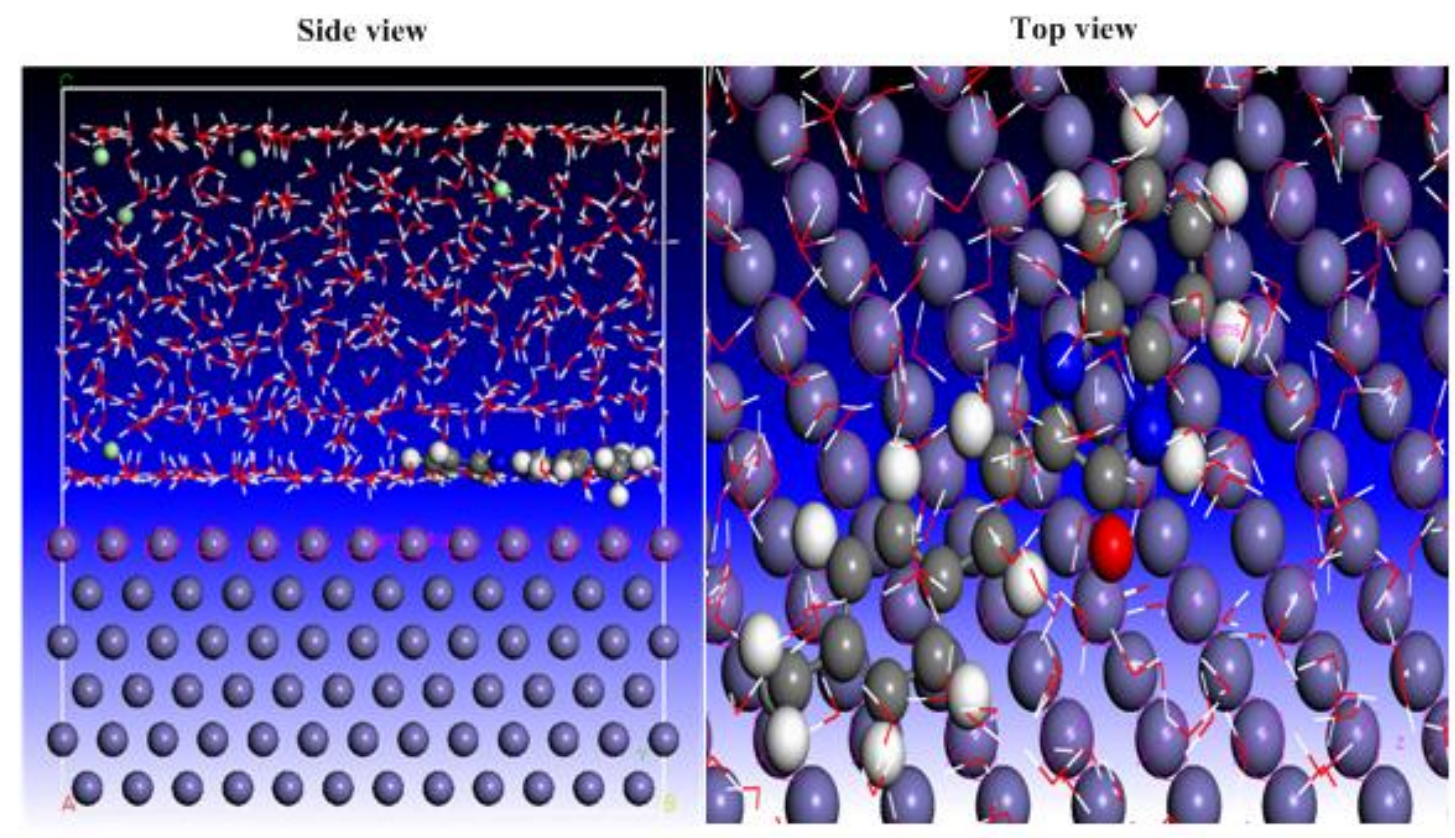

Figure 8. Top and side views of the best adsorption of the QNMS on the Fe (110) surface in acidic solution.

Table 5. Adsorption and interaction energies for the equilibrium adsorption configurations of the inhibitor molecule QNMS in studied system.

\begin{tabular}{ccccccc}
\hline Structure & $\begin{array}{c}\text { Adsorption } \\
\text { energy }\end{array}$ & $\begin{array}{c}\text { Interaction } \\
\text { energy }\end{array}$ & $\begin{array}{c}\text { QNMS: } \\
\mathbf{d} E_{\text {ads }} / N \mathbf{i}\end{array}$ & $\begin{array}{c}\mathbf{H}_{3} \mathbf{O}^{+}: \\
\mathbf{d} E_{\text {ads }} / \mathbf{d} N \mathbf{i}\end{array}$ & $\begin{array}{c}\text { water: } \\
\mathbf{d} E_{\text {ads }} / \mathbf{d} N \mathbf{i}\end{array}$ & $\begin{array}{c}\mathbf{C l}^{-}: \\
\mathbf{d} E_{\text {ads }} / \mathbf{d} N \mathbf{i}\end{array}$ \\
\hline QNMS & -5493.120 & 5632.659 & -150.321 & -147.890 & -9.319 & -1.368 \\
\hline
\end{tabular}

\section{Conclusions}

In the present investigation, the adsorption behavior of (E)-3-(4-methylstyryl)quinoxalin$2(1 H)$-one has been investigated using experimental and theoretical techniques. The important conclusions derived from the study are summarized as follows: The QNMS inhibit mild steel corrosion by forming a surface film at the metal/electrolyte interfaces. The percentage inhibition efficiency increases with increasing inhibitor concentrations of QNMS. The adsorption of QNMS on the metal surface follows the Langmuir adsorption isotherm. The potentiodynamic polarization study suggests that QNMS act as a mixed type inhibitor. The adsorbed QNMS film blocks the active sites present on the mild steel surface Quantum chemical calculations and experimental results are in good agreement.

\section{Acknowledgment}

The authors wish to thank the Moroccan Ministry of Higher Education for providing all the facilities and for supporting this work. 


\section{Notes}

The authors declare no competing financial interest.

\section{References}

1. C. Verma, M.A. Quraishi and A. Singh, J. Mol. Liq., 2015, 212, 804-812.

2. C. Verma, E.E. Ebenso, I. Bahadur, I.B. Obot and M.A. Quraishi, J. Mol. Liq., 2015, 212, 209-218.

3. M. Yadav, L. Gope, N. Kumari and P. Yadav, J. Mol. Liq., 2016, 216, 78-86.

4. A.A. Farag, A.S. Ismail and M.A. Migahed, J. Mol. Liq., 2015, 211, 915-923.

5. C.B. Verma, M.A. Quraishi and A. Singh, J. Taiwan Inst. Chem. Eng., 2015, 49, 229239.

6. A. Salhi, S. Tighadouini, M. El-Massaoudi, M. Elbelghiti, A. Bouyanzer, S. Radi and A. Zarrouk, J. Mol. Liq., 2017, 248, 340-349.

7. H. Zarrok, R. Salghi, A. Zarrouk, B. Hammouti, H. Oudda, Lh. Bazzi, L. Bammou and S.S. Al-Deyab, Pharma Chem., 2012, 4, no. 1, 407-416.

8. H. Zarrok, A. Zarrouk, B. Hammouti, R. Salghi, C. Jama and F. Bentiss, Corros. Sci., 2012, 64, 243-252.

9. M. El Hezzat, M. Assouag, H. Zarrok, Z. Benzekri, A. El Assyry, S. Boukhris, A. Souizi, M. Galai, R. Touir, M. Ebn Touhami, H. Oudda and A. Zarrouk, Pharma Chem., 2015, 7, no. 10, 77-88.

10. T. Zarnowski, Z. Kleinrok, W. Turski and S. Czuczwar, Neuropharmacology, 1993, 32, 895-900.

11. K.I. Priyadarsini, M.F. Dennis, M.A. Naylor, M.R. Stratford and P. Wardman, J. Am. Chem. Soc., 1996, 118, 5648-5654.

12. H.U. Gali-Muhtasib, M.J. Haddadin, D.N. Rahhal and I.H. Younes, Oncol. Rep., 2001, 8, 679-684.

13. H. Gao, E.F. Yamasaki, K.K. Chan, L.L. Shen and R.M. Snapka, Mol. Pharmacol., 2003, 63, 1382-1388.

14. I. Awad, J. Chem. Technol. Biotechnol., 1992, 53, 227-236.

15. D. Vullo, A. Innocenti，I. Nishimori，J. Pastorek，A. Scozzafava，S. Pastoreková and C.T. Supuran, Bioorg. Med. Chem. Lett., 2005, 15, 963-969.

16. M. Yadav, R. Sinha, S. Kumar and T. Sarkar, RSC Adv., 2015, 5, 70832-70848.

17. J.K. Landquist and G.J. Stacey, J. Chem. Soc., 1953, 0, 2822-2830. doi: 10.1039/ JR9530002822

18. W. Ried and S. Hinsching, Liebigs Ann. Chem., 1956, 600, no. 1, 47-59.

19. T. Laabaissi, H. Lgaz, H. Oudda, F. Benhiba, H. Zarrok, A. Zarrouk, A. El Midaoui, B. Lakhrissi and R. Touir, J. Mater. Environ. Sci., 2017, 8, 1054-1067.

20. M. El Faydy, M. Galai, M.E. Touhami, I.B. Obot, B. Lakhrissi and A. Zarrouk, J. Mol. Liq., 2017, 248, 1014-1027. 
21. H. Tayebi, H. Bourazmi, B. Himmi, A. El Assyry, Y. Ramli, A. Zarrouk, A. Geunbour, B. Hammouti and Eno E. Ebenso, Pharm. Lett., 2014, 6, no. 6, 20-34.

22. H. Tayebi, H. Bourazmi, B. Himmi, A. El Assyry, Y. Ramli, A. Zarrouk, A. Geunbour and B. Hammouti, Pharma Chem., 2014, 6, no. 5, 220-234.

23. P.E. Laibinis and G.M. Whitesides, J. Am. Chem. Soc., 1992, 114, 9022-9028.

24. A. Zarrouk, H. Zarrok, R. Salghi, R. Touir, B. Hammouti， N. Benchat, L.L. Afrine, H. Hannache, M. El Hezzat and M. Bouachrine, J. Chem. Pharm. Res., 2013, 5, no. 12, 1482-1491.

25. R. Haneda and K. Aramaki, J. Electrochem. Soc., 1998, 145, 2786-2791.

26. Y. Feng, W.K. Teo, K.S. Siow, Z. Gao, K.L. Tan and A.K. Hsieh, J. Electrochem. Soc., 1997, 144, 55-64.

27. A. Zarrouk, H. Zarrok, Y. Ramli, M. Bouachrine, B. Hammouti, A. Sahibed-dine and F. Bentiss, J. Mol. Liq., 2016, 222, 239-252.

28. L. Larabi, Y. Harek, M. Traisnel and A. Mansri, J. Appl. Electrochem., 2004, 34, 833839.

29. X.H. Li, S.D. Deng and H.J. Fu, Appl. Electrochem., 2010, 40, 1641-1649.

30. K. Juttner, Electrochim. Acta, 1990, 35, 1501-1508.

31. R. Macdonald and D.R. Franceschetti, in: Impedance Spectroscopy, Ed. J.R. Macdonald, Wiley, New York, 1987, p. 96.

32. D.A. Lopez, S.N. Simison and S.R. de Sanchez, Electrochim. Acta, 2003, 48, no. 7, $845-854$.

33. Z.B. Stoynov, B.M. Grafov, B. Savova-Stoynova and V.V. Elkin, Electrochemical Impedance, Nauka, Moscow, 1991 (in Russian).

34. A.Y. Musa, A.A.H. Kadhum, A.B. Mohamad and M.S. Takriff, Corros. Sci., 2010, 52, no. $10,3331-3340$.

35. K.S. Jacob and G. Parameswaran, Corros. Sci., 2010, 52, no. 1, 224-228.

36. N. Labjar, M. Lebrini, F. Bentiss, N. Chihib, S. El Hajjaji and C. Jama, Mater. Chem. Phys., 2010, 119, no. 1-2, 330-336.

37. X. Zheng, S. Zhang, W. Li, L. Yin, J. He and J. Wua, Corros. Sci., 2014, 80, 383-392.

38. M.A. Amin, K.F. Khaled, Q. Mohsen, H.A. Arida, Corros. Sci., 2010, 52, no. 5, $1684-$ 1695.

39. S. Martinez and M. Metikoš-Hukovic, J. Appl. Electrochem., 2003, 33, 1137-1142.

40. F. Bentiss, M. Lebrini, M. Lagrenee, M. Traisnel, A. Elfarouk and H. Vezin, Electrochim. Acta, 2007, 52, 6865-6872.

41. M. Lebrini, M. Lagrenee, H. Vezin, M. Traisnel and F. Bentiss, Corros. Sci., 2007, 49, 2254-2269.

42. H. Zarrok, A. Zarrouk, R. Salghi, M. Ebn Touhami, H. Oudda, B. Hammouti, R. Touir, F. Bentiss and S.S. Al-Deyab, Int. J. Electrochem. Sci., 2013, 8, 6014-6032.

43 A.K. Satapathy, G. Gunasekaran, S.C. Sahoo, K. Amit and P.V. Rodrigues, Corros. Sci., 2009, 51, no. 12, 2848-2856. 
44. M. Chevalier, F. Robert, N. Amusant, M. Traisnel, C. Roos and M. Lebrini, Electrochim. Acta, 2014, 131, 96-105.

45. A.S. Yaro, A.A. Khadom and R.K. Wael, Alexandria Eng. J., 2013, 52, no. 1, 129-125.

46. J. Bhawsar, P.K. Jain and P. Jain, Alexandria Eng. J., 2015, 54, no. 3, 769-775.

47. M. El Faydy, M. Galai, A. El Assyry, A. Tazouti, R. Touir, B. Lakhrissi and A. Zarrouk, J. Mol. Liq., 2016, 219, 396-404.

48. S. Issaadi, T. Douadi and S. Chafaa, Appl. Surf. Sci., 2014, 316, 582-589.

49. L. Guo, S. Zhu, S. Zhang, Q. He and W. Li, Corros. Sci., 2014, 87, 366-375.

50. M. Frisch, J.G.W. Trucks, H.B. Schlegel, G.E. Scuseria, et al., Gaussian 09, Revision A.01, Gaussian, Inc., Wallingford CT 2009.

51. J. Zhang, Z. Liu, G.-C. Han, S.-L. Chen and Z. Chen, Appl. Surf. Sci., 2016, 389, 601608.

52. N.O. Eddy, E.E. Ebenso and U.J. Ibok, J. Appl. Electrochem., 2010, 40, 445-456.

53. L.O. Olasunkanmi, M.M. Kabanda and E.E. Ebenso, Phys. E (Amsterdam, Neth.)., 2016, 76, 109-126.

54. L.O. Olasunkanmi, I.B. Obot, M.M. Kabanda and E.E. Ebenso, J. Phys. Chem. C, 2015, 119, 16004-16019.

55. V. Sastri and J. Perumareddi, Corrosion, 1997, 53, 617-622.

56. D.Y. Ryu and M.L. Free, Anti-Corros. Meth. Mater., 2006, 53, 12-18. 